\title{
The art, poetics, and grammar of technological innovation as practice, process, and performance
}

\author{
Mark Coeckelbergh ${ }^{1}$
}

Received: 7 February 2017 / Accepted: 11 March 2017 / Published online: 25 March 2017

(C) The Author(s) 2017. This article is an open access publication

\begin{abstract}
Usually technological innovation and artistic work are seen as very distinctive practices, and innovation of technologies is understood in terms of design and human intention. Moreover, thinking about technological innovation is usually categorized as "technical" and disconnected from thinking about culture and the social. Drawing on work by Dewey, Heidegger, Latour, and Wittgenstein and responding to academic discourses about craft and design, ethics and responsible innovation, transdisciplinarity, and participation, this essay questions these assumptions and examines what kind of knowledge and practices are involved in art and technological innovation. It argues that technological innovation is indeed "technical", but, if conceptualized as techne, can be understood as art and performance. It is argued that in practice, innovative techne is not only connected to episteme as theoretical knowledge but also has the mode of poiesis: it is not just the outcome of human design and intention but rather involves a performative process in which there is a "dialogue" between form and matter and between creator and environment in which humans and non-humans participate. Moreover, this art is embedded in broader cultural patterns and grammars-ultimately a 'form of life' - that shape and make possible the innovation. In that sense, there is no gap between science and society - a gap that is often assumed in STS and in, for instance, discourse on responsible innovation. It is concluded that technology and art were only relatively recently and unfortunately divorced, conceptually, but that in practices and performances they were always linked. If we
\end{abstract}

Mark Coeckelbergh

mark.coeckelbergh@univie.ac.at

1 Department of Philosophy, University of Vienna, Universitätsstrasse 7 (NIG), 1010 Vienna, Austria understand technological innovation as a poetic, participative, and performative process, then bringing together technological innovation and artistic practices should not be seen as a marginal or luxury project but instead as one that is central, necessary, and vital for cultural-technological change. This conceptualization supports not only a different approach to innovation but has also social-transformative potential and has implications for ethics of technology and responsible innovation.

Keywords Technology - Innovation - Art - Poiesis . Techne $\cdot$ Performance $\cdot$ Participation · Grammar · Form of life $\cdot$ Epistemology $\cdot$ Practice

\section{Introduction: the gap between technological innovation and art, and the idea of technological innovation as design}

In the past decades, artists have used all kinds of new technologies to create their art. Many artists integrate the methods of art and the methods of science. Moreover, there are more research projects and businesses now that link technological innovation to art. Art and technology labs are set up at art institutions and universities. Some of them have been around for a while, such as the MIT Media Lab and the Ars Electronica FutureLab. There is growing discourse on transdisciplinary and even 'antidisciplinarity' (Oxman 2016), and there is more interest in practice-led research which may include, for instance, the performance of images, sound, and code rather than only doing things with numbers or words (Haseman 2006). Inside and outside academia, there is also more attention to craft work and craft culture, which also links art, science, innovation, and design. Consider for instance fab labs, which enable DIY 
digital fabrication or the current interest in craft culture in architecture (e.g. Francisco 2007). This development has a long history which in modern times goes back to, for instance, the Arts and Crafts movement in the nineteenth century; it is also connected to a history of discourses about these practices (Lees-Maffei and Sandino 2004).

However, that such developments, collaborations, and cross-overs are presented as new or exceptional is only possible on the basis of a widely shared assumption in academia and in the general public that previously and even today these are two very distinct domains with distinct methodologies. More generally, in modern society science and culture are seen as separate areas, and this assumption continues to exert its influence on the way we organize knowledge and innovation practices. For instance, in academia, the study of nature (natural sciences) is still largely disconnected from the study of culture (humanities and social sciences). Academic programmes that connect both domains are still the exception. And even today, often science is still seen (by many philosophers and others) as objective and detached, directed towards the universal, whereas art is seen as subjective and engaged, directed towards the particular. Technological innovation, then, is supposed to follow the methods of science rather than art, or at least to draw on knowledge established by the sciences. (In this understanding, engineering is seen as applied science.)

Furthermore, thinking about technological innovation in the context of engineering and product development-my focus here is on the technological innovation as invention rather than economic innovation in the sense of finding new markets and business opportunities ${ }^{1}$ —is often guided by the view that it is about "design", in the sense of ideas and concepts that are then materialized. It is about humans having ideas that then form matter or even create something entirely new that did not exist before. Innovation brings in the new. But what is new? A concept, a model, a form. What matters is a new idea. Similarly, in contemporary art it is often assumed that the artist needs to have a "concept", which then is materialized in objects, installations, etc.

This conception of innovation and invention seems to be somewhat similar to the ancient mythologies (e.g. in Mesopotamia or in ancient Greece) in which a god or gods act upon existing matter or even create ex nihilo-Genesis $1: 1$ is often interpreted as such. What matters in these accounts, it seems, is the concept held by the creator, which

\footnotetext{
${ }^{1}$ For instance, Garcia and Calantone (2002) define innovation as 'an iterative process initiated by the perception of a new market and/or new service opportunity for a technology-based invention which leads to development, production, and marketing tasks striving for the commercial success of the invention.' (p. 112).
}

is then materialized. It also reminds us of the Platonic figure of the demiurge, the craftsman who created the physical universe out of created or uncreated matter. In the Timaeus, Plato sees the demiurge as someone who has a concept and then uses that to shape matter. However, here there is no modern conception of art as the expression of the artist, or the idea that the artist invents something entirely new; at this point, the idea is still that the artist uses a pre-existing form which is then imposed on formless, orderless matter. In this pre-modern approach, there is already an eternal form, a model. In any case, regardless of where the concept comes from, in these views art is about the imposition of concept on the physical world, form on matter. (Note also that there is not yet a distinction between "fine arts" and crafts.) This also assumes that the process of innovation as creation is under control of the craftsman/artist- today the "designer"- who imposes on the material. The etymology of "design" also points in that direction, which has meanings linked to marking, project, and purpose. The modern designer creates a concept, marks out a concept or scheme, which then gets realized and executed. The designer is in control of that idea; it is not dependent on its execution or whatever else happens with it.

For instance, according to these views, coding is seen as applied computer science that is very different from artistic practices and involves a know-how that is an application of theoretical knowledge gained in computer science. Artists, it seems, have no business in this process. Moreover, innovation in this area, for instance the creation of a new app, is seen as creating a new concept which is then implemented in code and in hardware. The hardware is "passive", so to speak. Another example is the invention and design of a new robot, which is also assumed to be the application of scientific knowledge and as the invention of a new concept, an idea, which then shapes matter in the sense that form is translated into code which in turn shapes material hardware. In other words, in all these cases there is always a one-directional movement starting with the creator's concept and ending up in material reality, which is shaped by the innovator's concept. Form is imposed on matter; human intention and imagination are materialized.

This essay challenges these assumptions by examining what kind of knowledge and practices are involved in art and in technological innovation. Drawing on work by Dewey, Heidegger, Latour, and Wittgenstein, it argues that technological innovation, if conceptualized as techne, can and must be understood as art and performance. It is argued that in practice technological innovation does not only involve episteme as theoretical knowledge and concept (which is then applied, as in "forms shapes matter") but also has the mode of poiesis, in which there is a kind of "dialogue" between form and matter, and between innovator and environment, which is in some ways (but not in 
other ways) similar to natural growth. This understanding of technological innovation closely links it to art, which also involves poiesis. Further reflections on this concept lead to the thesis that technological innovation is not just the outcome of human design and intention but rather involves a performative process in which humans and nonhumans participate, and which is embedded in broader cultural patterns and grammars-and ultimately a form of life-that shape and make possible the innovation. The essay thus challenges those in academia and elsewhere who still hold on to the assumption that there is and should be a divorce between technological innovation and art, and contributes to ongoing efforts in art, philosophy of technology, design, and elsewhere that try to reconcile what in practices and performances has never really been separated: art and technology, science and culture, subjects and objects.

First I question the separation between technological innovation and art by drawing on Dewey's views, enabling us to see both art and technology as involving a similar kind of practice, which is inherently social. Also in this sense, they are not separate domains, as is often assumed in modernity. Stronger: science and technologies are branches of art. Then I turn to the ancient Greek terms techne and poiesis and to Heidegger and Latour to further develop a bridge between art and technology, and indeed a bridge between humans and non-humans. Technological innovation turns out to be more poetical than usually assumed. Both technological innovation and art are seen as poetic and performative processes and practices. Finally, I use Wittgenstein to argue that practices of technological innovation are embedded in wider cultural grammars, questioning again the so-called gap between science and society assumed in, for instance, discourse on responsible innovation. While this discussion covers a rather wide range of thinkers and diversity of perspectives and deserves further development in a larger work, I show that we can already use these various conceptual building blocks to construct conceptual links between technological innovation and art. It is concluded that by using concepts such as practice, techne, poiesis, and form of life, technological innovation and art can be seen as having always been connected. It is hoped that this conceptual work helps justify, motivate, and support current efforts in art and science to create bridges between technological innovation and artistic practices.

\section{Technology as art: thinking together art and technology with Dewey}

In Experience and Nature (1925), Dewey questions the Western (in particular: ancient Greek, Platonic) identification of knowledge with contemplation, which has led to the exclusion of 'trial, work, manipulation and administration of things' (p. 124). This exclusion is rooted in a metaphysical division between means and ends: things have always been seen as 'slavish' means, whereas ends are independent. The practice of knowing is seen as inferior, the useful arts are 'assigned a lower rank' (p. 357). The division between means and ends also reflects a social division between 'working and leisure classes' (p. 368). Against this division, Dewey argues that 'in the practice of science, knowledge is an affair of making sure, not of grasping antecedently given sureties' (p. 154). Against the view that knowledge is contemplation instead of 'a productive art' (p. 357), against the division between theory and practice, and against the division between the (practical) artistic and the (contemplative) aesthetic, between crafts and fine arts, Dewey puts the emphasis on art and sees science as art and practice:

It would then be seen that science is an art, that art is practice, and that the only distinction worth drawing is not between practice and theory, but between those modes of practice that are not intelligent, not inherently and immediately enjoyable, and those which are full of enjoyed meanings. (...) Thus would disappear the separations that trouble present thinking: division of everything into nature and experience, of experience into practice and theory, art and science, of art into useful and fine, menial and free. (Dewey 1925, p. 358)

For Dewey, even thinking itself is an art: 'knowledge of propositions which are the products of thinking, are works of art, as much so as statuary and symphonies' (p. 378). Knowledge, then, is an art and an 'act' (p. 381), the act of knowing, which produces 'new modes of interaction' (p. 382). One could interpret this as saying that knowledge and art, considered as practices, are performances leading to what Dewey calls 'objective transformation', which is 'the method of action in the arts and sciences' (pp. 345-346). If science is an art, then it must be placed within the history of arts:

The history of science in its distinct emergence from religious, ceremonial and poetic arts is the record of a differentiation of arts, not a record of separation from art. (Dewey 1925, p. 388)

For thinking about technological innovation and art, this view means at least the following. First, the separation between technological innovation and art is unfruitful, since both can be understood as arts, practices, and performances, which must be placed within the history of a differentiation of arts. In addition, if science is itself also a practice and an art, then science and technology should also not be seen in terms of theory and practice, contemplation and application, master and slave. Technological innovation 
should then not be seen as ranking "lower" than science; it is not the servant of science who applies its theory and concepts, but is another practice that also contributes to better knowledge and experience. Second, the Platonic conception of innovation and design as the creation of a detached concept (perhaps seen in contemplation), which is then put into practice, materialized, executed, and so on, must also be questioned. Instead, in this view successful innovation is a performance that necessarily involves practical work, performances with things, aimed at objective transformations. Then 'trial, work, manipulation and administration of things' is not to be seen as work that needs to be done by those who execute the design received from the innovator, designer, or artist-the "slaves" of the innovator, designer, or artist so to speak-but as makings necessary for the innovation itself. Moreover, this renders the process open to participation of users, who can participate in the making, which is part of the process of innovation and invention. It leads to a different view of innovation that is more participative and inclusive and hence has the potential of social transformation.

It is also a view that ties in with visions of responsible innovation (e.g. Von Schomberg 2013) that stress participation of stakeholders, public engagement, and democracy (e.g. Owen et al. 2012), and with the recent history of participative research, based on the recognition or even moral and political 'imperative' that humans have the fundamental right to contribute to decisions that affect them (Reason 1998). The difference with the proposed conception of innovation, however, is that here participation is not an imperative that needs to be added from the "outside", so to speak, but is rather seen a feature of good innovation, design, and art itself: a necessary feature of innovation as performance.

Whereas this non-Platonic and more egalitarian conception of innovation and art is relatively unknown by the general public, we see that both in art and in innovation artists and designers increasingly work like this. They may have "concepts", but these concepts interact with, and at least partly emerge from, concrete engagement with the material and from collaborations with production and with people busy with production. For instance, today innovative architecture-itself a practice on the border between art and innovation-often includes engagement with the "trial, work, manipulation and administration of things' at various stages of production of a building. The architect is then no longer a Platonic concept-contemplator but becomes more like a participant in a more inclusive performative process that leads to objective transformation. Another example is when the design of an artefact/work of art involves interaction between an initial concept of a particular artist and collaborations with people at various places in the world that result in an artefact/work of art (or several works of art) that is more than mere "executions" of a pre-established idea. To the extent that this happens (the Platonic conception is still very influential), these artists-innovators continue a long history of the arts (in the plural), which is not so much about contemplation but about practical-experiential processes involving different kinds of know-how and practical experience-know-how and work that is linked to all kinds of people and skills, which work together more or less on a basis of equality. Moreover, we can then also recognize that design, art, and "even" science are collaborative practices involving know-how and implicit, 'tacit' knowledge and intuition (Polanyi 1966a, b) based on practical experience and collaboration with others-going against the tendency of designers to assert their individual role (Rust 2004). And as said, users can also take part in these innovation processes, since in this approach their experience matters.

\section{Techne as poiesis: using Heidegger and Latour to conceptualize practices of technological innovation as a poetic, participative, performative, and political process involving humans and non-humans}

Another way to bring together technological innovation and art, and to further develop the Deweyan view presented in the previous section, is to further reflect on the Greek terms techne and poiesis (here with the help of Heidegger) and to link both Heidegger and Dewey to Latour.

Technological innovation refers to the term "technology", which in turn is rooted in the ancient Greek term "techne". The term techne can be interpreted as technologos in the sense that there is "first" a logos, which then materialized and executed. In other words, it can be conceptualized in terms of Platonic design as outlined above. However, it can also be interpreted as a kind of poiesis. Let me develop this by drawing on Heidegger.

The ancient Greeks distinguished between physics, techne, and poiesis. The usual translation/interpretation of these terms goes as follows: Physis refers to change in non-human nature which is not under human control (for instance growth), whereas techne is a kind of making that involves a human goal and intention. Poiesis, then, can be defined as a mix of physics and techne: from techne it has the aspect of human making, but at the same time the process of making is not entirely under human controllike in physis. However, is techne really only about human intention? Is techne to be interpreted as human design? In 'The Question Concerning Technology' (1977), Heidegger argues that techne belongs to poiesis since, like physis, it has 'the bursting open belonging to bringing-forth, e.g. the bursting of a blossom into bloom' (Heidegger 1977, p. 10) but in contrast to physics this bursting open does not 
happen 'in itself' but 'in another (en alloi), in the craftsman or artist' (p. 11). This conception of techne still relates techne to a human craftsman or artist, but interestingly here the human is a mere participant in the artistic/techne process. The work of art or the artefact is not exclusively the result of human intention, it also involves-so we may interpret Heidegger-the "participation" of the material. There is a process of making and revealing in which both humans and non-humans take part.

Heidegger uses this view of techne within his more general argument about modern technology, which contrasts modern technology with the ancient craft work. But whether or not we accept his particular view of modern technology (I will argue that modern technological innovation is less modern than it seems), his conception of techne as poiesis can help us further develop the Deweyean view presented in the previous section. Like Dewey, Heidegger points to a time when 'the arts were not derived from the artistic. Art works were not enjoyed aesthetically' (p. 34) in other words, to a time when there was not yet a division between aesthetic contemplation and art as practice. There were artistic-technical practices. According to Heidegger, this changes in modern times. But with Dewey and, as I will show now, with Latour, we can argue that we still have techne, that also modern technology depends on techne, understood as poiesis, that we have never been modernto use Latour's phrase (Latour 1993). In particular, we can use Heidegger to emphasize that also today technological innovation, like art, is not what we moderns (and we Platonists) take it to be. We believe that technological innovation, design, and art is all about creating a concept, which then gets materialized; that there is an idea which then needs slaves to become material objects. But we can interpret Dewey, Heidegger, and Latour as implying that instead there is, and always has been, a practical-performative process in which both humans and non-humans participate, and which is not totally in control of the human and not entirely a result of human goals and intentions. In other words, if the techne involved in technological innovation is not fundamentally different from that involved in art, technological innovation is more poetical than assumed. There is a transformative and revealing encounter with matter, or "dialogue" with matter, in a process and performance of poetical bringing-forth, in which human will and intention does not necessarily play the major part. In innovation, there is rather a responding to the material and a participation in a process of unfolding.

This less modern understanding of innovation and art-indeed innovation $a s$ art and as poetic techne-is in line with Latour $(1993,2004)$, who has interpreted science and society in a way that, like Dewey, questions modern distinctions between nature and the social, and helps us bring together humans and non-humans in our conception of technological innovation as art. Latour has argued that in spite of modern attempts to "purify" science and society, scientists have always created hybrids of nature and culture, nature, and the social (Latour 1993). $\mathrm{He}$ arrived at this view by studying concrete practices and networks in the laboratories of scientists, where he found non-modern hybridity rather than "things-in-themselves" or "society" (p. 25). He sees 'nature-cultures' and 'collectives' (Latour 2004, p. 45), 'assemblages of humans and nonhumans' (p. 52). The social is made up of actors and 'actants' (pp. 76-77). Thus, the social involves both humans and non-humans, and science can once again be seen as a practice and a craft. Furthermore, at the level of interaction with technology in such craft work, there may also be hybridization between humans and things, as Verbeek (2014) has stressed with regard to design. Humans and non-humans may interact in various ways, and this can include merging and immersion; this process does not only constitute (non-human) objects but also (human) subjects. To conclude, like in Dewey the claim is that modern distinctions and divisions do not hold once we look at the level of practice and (I add) performance.

Indeed, using Pickering (1995) we can stress the performative aspects of Latour's view of the social: instead of a static ontology, we can see science as performances involving both 'human and material agency' (Pickering 1995 , p. 21), constituting 'a posthumanist space, a space in which the human actors are still there but now inextricably entangled with the nonhuman, no longer at the center of the action and calling the shots. The world makes us in one and the same process as we make the world' (p. 26). In this view, humans and machines 'collaborate in performances' (p. 16); science becomes 'a dance of agency' (p. 21). Material agency is entangled with human agency, and neither is reducible to the other (p. 54). Humans plan and have goals and intentions, but in practice there is 'interplay here between the emergence of material agency and the construction of human goals' (p. 56).

For Latour, this also raises political questions regarding the voice of things (Latour 2004). Like Dewey asked the question regarding equality of humans, on the basis of Latour's view the question regarding equality of humans and non-humans can be raised: if both humans and nonhumans play this more "active" role not only in science but also in the social more generally, is it right that we see ourselves as the masters of things, that we see things as our slaves? (And maybe this question is even more Deweyan than expected, if we interpret his remark about means and ends, where means are seen as slaves, as not only a political gesture concerning relations between humans but also as concerning non-humans. Did Dewey argue for a liberation of the means, and can this be interpreted not only as a call 
for liberation of human workers but also as a call for liberation of things in a Latourian sense?)

Applying this view of science to innovation and art, this approach means that in practice both innovation and art are to be understood as involving actors and 'actants'. Then material things are no longer merely "passive" recipients of a "concept" or "design" imposed by the (contemplative, intuitive, perhaps also: "genius") innovator or artist, but play a more "active" role in the innovative-artistic practices and performances from which an innovative artefact or original work of art emerges. There is one space in which there is human agency and material agency. Goals of humans, "concepts", "designs", etc. still play a role. But the actual innovation and the actual work of art emerge through dances and dialectics between human and nonhuman performances. The artist responds to the material. And the material may cooperate or resist, afford certain things rather than others, move in certain directions rather than others, etc. The material-if we must use the term at all-thus "co-designs" the product. Moreover, Latour's view, like Dewey's, also helps us connect this poetic, performative, and non-modern epistemology to the question concerning the social. With Latour, we can go further than Dewey (or indeed fully understand and think through the radicality of Dewey's project) and see the social no longer in exclusively human terms, but also add non-humans to the social. The result is a view of innovation and art which does not only raise social and political questions about, for instance, equality between humans, but also asks about the social relation between humans and non-humans (at least if and in so far they are not merged). Should things be mere slaves and receptacles of our will, intention, and "concepts", or should we see them as a kind of "partners" (dance partners, performance partners) when it comes to technological and artistic innovation, understood as poiesis? Whether or not we endorse the second view, at least this approach raises the question, which is an epistemological and a social question at the same time. Again questions regarding knowledge are seen as intrinsically connected to the social question, and questions regarding "technological" innovation turn out to be, at the same time, questions regarding social transformation.

\section{Innovation as performance embedded in a form of life: using Wittgenstein to connect practices of technological innovation to wider cultural grammars}

We can also say more about the social dimension of innovation as practice, art, and poiesis by using Wittgenstein. With Dewey, Heidegger, and Latour, we have already arrived at a more holistic and social view of innovation: innovation is indeed something "technical", but if we understand the techne in the ways I proposed, then this "technical" innovation is linked to larger epistemic and social processes and challenges. It is no longer about detached contemplation or creation of a "concept" alienated from practical, material, and social reality and performances. It is not a theoretical matter divorced from the practical dances and mangles (to use Pickering's term) with material things. It is also not about "art" if "art" is understood in terms of aesthetic contemplation or the "fine" arts as opposed to crafts. It is also not about science if science is understood in a theoretical-contemplative way. Instead, it is about knowledge, science, and art at work, about skill and know-how, about making truth, about knowing (verb) and about social transformation.

This interpretation can be further elaborated using Wittgenstein's view of language and applying it to technology and technological innovation. In the Philosophical Investigations (2009), Wittgenstein argued that language must be understood in analogy to the use of tools:

Think of the tools in a toolbox: there is a hammer, pliers, a saw, a screwdriver, a rule, a glue-pot, glue, nails and screws-The functions of words are as diverse as the functions of these objects. (And in both cases there are similarities.) (Wittgenstein 2009, § 11, p. 9e)

He also calls language 'an instrument': 'Language is an instrument. Its concepts are instruments' ( $\$ 569$, p. 159e). According to Wittgenstein, language is about use. It is use that gives signs life and breath ( $\$ 432$, p. $135 \mathrm{e})$. But, interestingly, for Wittgenstein this use is always related to larger wholes and contexts. In particular, he argues that use of words is linked to 'language-games' and a 'form of life': He writes:

I shall also call the whole, consisting of language and the activities into which it is woven, a "languagegame”. (§ 7, p. 8e)

According to Wittgenstein, our use of language is shaped by the activities and games we play, which itself has a larger context, a 'form of life':

to imagine a language means to imagine a form of life. $(\S 19,11 \mathrm{e})$

If we learn a language, we do not use theoretical knowledge. We learn language in the same way as we learn other skills, which are always linked to activities, social games, and a form of life. These activities and games have rules and one must know some things. But what kind of knowledge, exactly, is required? In $\mathrm{On} \mathrm{Cer}$ tainty (1969), Wittgenstein suggests that we do not need theoretical knowledge in our everyday lives in order to 
learn language and the social life, but rather-and here he is in line with Dewey-we need experience. Learning a language is a matter of mastery: to master a languagegame is to be able to do certain things ( $\$ 534$, p. 71e). This does not require theoretical knowledge (which can then be doubted); instead, we lead our lives while 'being content to accept many things' ( $\$ 344$, p. 44e), without having certainty. Moreover, against the stress on rule in the later Wittgenstein (or at least in many of his interpreters) but in line with Polanyi, we must stress that not all knowledge can be made explicit. Language, but also the grammars in which it is embedded such as games and a form of life, is a matter of know-how, which can only partly be formalized.

This is a view about language (and, like Dewey, Heidegger, and Latour, a view about epistemology), but I propose we can turn Wittgenstein's metaphor around and use it to say something meaningful about technology and technological innovation. Technology, if understood as the use of tools, can also be linked to activities, games, and forms of life. The use of tools is not isolated from the practical and social life, but is instead part of it and shaped by it. Learning to use a technology is like learning to use a language: it requires skill, but this "technical" skill is not isolated from larger social wholes. Instead, using a technology requires experience, which is always at the same time a social experience, since use of the technology is connected to games and, ultimately, to a form of life. Use of technology, then, is always shaped and made possible by larger social "grammars". [Consider also Wittgenstein's use of the term grammar, in particular 'depth grammar' (Wittgenstein 2009 , § 664, pp. 176e-177e).] Technology use is related to a larger social-cultural whole, to "how we do things". Taking into account Polanyi's point, however, we must add that we can try to make these grammars explicit, but that there is also a lot of implicit knowledge involved in this knowing how to use technology. Moreover, elaborating Wittgenstein's insights we can say that the games and grammars, in which technology is embedded and by which it is shaped, are always also normative. This normativity can be explicit, in the form of rules (and indeed in the later Wittgenstein the stress is on rules), or it can be implicit, in the form of ways of doing things and in the form of cultural meanings, values, and other "grammars" that are not always made explicit.

This use of Wittgenstein for thinking about technology (see also Coeckelbergh 2017) is in line with Winner's application of Wittgenstein's concept 'form of life' to technology. In 'Technologies as Forms of life' (2014), Winner argued that technologies 'become woven into the texture of everyday existence' and then 'shed their tool-like qualities to become part of our very humanity' (Winner 2014, p. 55). They bring about 'significant alterations in patterns of human activity and human institutions': technologies make 'new worlds' (p. 54):

We do indeed "use" telephones, automobiles, electric lights, and computers in the conventional sense of picking them up and putting them down. But our world soon becomes one in which telephony, automobility, electric lighting, and computing are forms of life in the most powerful sense: life would scarcely be thinkable without them. (Winner 2014, p. 54)

At the same time, the forms of life in which new technologies enter and are embedded also shape our use. There are already older cultural and social patters. Winner gives the example of our use of computers:

Forms of life that we mastered before the coming of the computer shape our expectations as we begin to use the instrument. One strategy of software design, therefore, tries to "humanize" the computers by having them say "Hello" when the user logs in or having them respond with witty remarks when a person makes an error. We carry with us highly structured anticipations about entities that appear to participate, if only minimally, in forms of life and associated language games that are parts of human culture. (Winner 2014, p. 56)

Thus, we must place technologies in the context of the 'vast multiplicity of cultural practices that comprise our common world' (p. 57). They are not only "technical", or rather, because they are "technical", they also shape our world and our thinking. Winner suggests that the way people talk about themselves has been influenced by the computer, for instance when we compare the mind to a computer (p. 58).

Applied to technological innovation, then, this Wittgensteinian view implies that innovation and art must themselves be understood as involving the use of tools, and that in this respect they are linked to activities, games, and a form of life. These games and forms of life shape, structure, and make possible the innovation, and bring with them particular meanings, expectations, and normativities. Innovation should not be reduced to the (conceptual or contemplative) "act" of the innovator; instead, if we understand it in practical terms as proposed in the previous sections, and if we then conceptualize this practice as use understood in a Wittgensteinian sense, we can conclude that innovation is always embedded in the "vast multiplicity of cultural practices that comprise our common world' (to use Winner's phrase again), embedded in activities, games, and a form of life. (And the same could be said about art, or rather: about other arts.) If we want to arrive at a more comprehensive conception of technological innovation, then we also have to include the structures and "grammars" that 
shape it, and that are in turn shaped by the innovation. If technological innovation is a matter of "design" at all and involves the use of "concepts", that design and those concepts are not to be seen as a creation ex nihilo, but as uses and performances that participate in games and in a larger social-cultural whole that always precede the innovative "act" and structure it. Innovation might be a matter of performance and agency, but it is always a performance that is inscribed, prescribed, and "co-scripted" by those larger wholes. Therefore, the epistemology of technological innovation should not only be formulated in terms of personal experience, learning, and skill, but also a particular "local" practice and poetic process. That personal experience and "local" technical-poetic experience, process, and performance are always shaped by what is already given: in existing games, in a form of life, in all kinds of grammars that structure and make possible the particular innovation. Again the demiurge model of innovation and invention, and especially the creation ex nihilo interpretation of that demiurge model, is challenged. If we must use the figure of the demiurge at all, the demiurge act of creation and design needs to be made practical and performative, rather than Platonic and contemplative, and it needs to be emphasized-here by using Dewey, Heidegger, and Wittgenstein - that the creation is not ex nihilo and independent, but instead responds to the material and to social and cultural structures that are already in place "before" there is the act of creation.

Both the Deweyean and the Wittgensteinian approach to innovation proposed here thus question the assumption, widely held in STS and in discourses about responsibility innovation, that there is a gap between science and society. There is no gap in the sense that innovations are always already embedded in social forms and structures. If there are problems that are framed in terms of a gap, these problems are only possible since there is already a connection. For instance, if technological innovation is said to be moving away from social values, then this has not only to do with innovation, but with what happens in society and to the values in society. Value changes in society make possible value changes in innovation.

Furthermore, for the views of technological innovation articulated in the previous sections, this support for yet another "social" conceptualization of the technical and of innovation also means that although technological innovation has always the potential of social transformation (since it is already social by nature), at a fundamental level there cannot be a radical transformation. If one wished to change the master-slave situation mentioned before (a desire for change that is perhaps inspired by Dewey and Latour), for instance, and indeed if one wished to change the very way we think about means and ends, nature and society, and so on, then one must bear in mind that the given structures and grammars exert a powerful influence on our innovations and on us-including a normative influence. Radical change seems to be difficult then, if not impossible.

On the other hand, if we understand innovation in a more practical and performative sense, as proposed in the previous sections, then there is some hope for concrete (but perhaps smaller) changes. If we do not understand innovation in terms of an idea or concept (e.g. the idea to liberate human and non-human slaves) which then needs to get executed (and which then turns out to be difficult), but instead understand it in terms of material-social practices and performances, then one could conclude that the only truly innovative in both technical and social senses can only happen in these practices and performances, which will always involve "local" dialogues and interactions with things and people, but which will also always necessarily involve dialogue and interaction with the social and cultural "grammars" that shape these practices and performances. New innovative practices may then slightly alter the relevant games and form of life, which should not be reified but which "live" only in and as practices-including technological, artistic, and design practices. But this kind of change is a slow process which has uncertain and unpredictable outcomes. It seems that this is the "only" way social transformation can happen.

It is also probably the best way. Even if it was possible to turn around every stone (to paraphrase Popper), even if it was possible to impose one's concept of social transformation onto the material and social world, such a Platonic and totalitarian act would be very dangerous and undesirable. Politically speaking, the approach to technological innovation and art presented here intends to enable a non-totalitarian approach to social change and transformation. Since it is explicitly opposed to total and Platonic design, it is also non-utopian in Popper's sense articulated in The Open Society and Its Enemies (1962). Popper read in Plato 'the sweep of Utopianism, its attempt to deal with society as a whole, leaving no stone unturned' (Popper 1962, p. 7). This is not the kind of innovation we want or need, although on the basis of what I said here we must reject Popper's alternative: a 'completely abstract or depersonalized society' (p. 174). The approach I propose questions both the totalitarian and the abstracting aspects of Plato.

\section{Conclusion: technological innovation as a poetic, participative, and performative process vital for cultural-technological change}

In this essay, I have attempted to conceptualize a bridge between technological innovation and art. Using Dewey, Heidegger, and Wittgenstein, I have interpreted technological innovation as a poetic, participative, and performative 
process, which is always already connected to a wider cultural context, which makes possible and constrains that process. This has yielded a conception of innovation that goes against a long-standing and ancient tradition, which holds a dualistic view of innovation as involving a split between, on the one hand, an idea, model, concept, etc. and, on the other hand, material reality formed by that concept. Instead, in the approach I propose, there is a kind of "dialogue" between concept and material, mind and matter. Moreover, both my application of Wittgenstein's term form of life and the idea of innovation as techne and poiesis (inspired by Heidegger) also imply that humans have not complete control over innovation: it is a participative, social, and cultural process which depends on larger cultural structures and which involves human and non-human performances. Technological innovation is also not a static affair but a process, and with Dewey we can say that it is a practical affair which is very similar, if not identical, to art. Indeed, technological innovation and science can be seen as branches of the development of the arts. This means that current efforts in both art and science/technology to bridge the gap between these two domains can be supported and justified by a coherent argument about the nature of, and relation between, technological innovation and art. I have presented such an argument here, and I have shown that and how we can use a variety of philosophical-theoretical resources to support it. While of course more work is required to further develop these various conceptual routes, I hope that the present text may contribute to current discourses and ongoing and growing practical efforts in the arts and in technological innovation that also try to build bridges. Such efforts and experiments, then, are neither a luxury or a marginal hobby, nor are they exceptional or new; they are instead central to what innovation, understood as techne and poiesis, is all about. Finally, based on Dewey and Latour we can understand the transformative potential of technological innovation in and for society; however, with Heidegger and Wittgenstein we should also acknowledge that this social change, through innovation, has its limits, since there is already a given culture, a form of life, which constrains - but also makes possible-innovation.

For ethics of technology and for responsible innovation, for instance, this approach means that we have now more fundamental support for the claim that designers, engineers, artists, and so on should be held responsible for what they do and that they should think about ethics and responsibility before and when they design and innovation. We can now explain and justify this claim by saying that they have this responsibility precisely since innovation is intrinsically material and social: if we understand innovation as already itself social, then innovation has already the potential of, and contribution to, social transformation. Yet at the same time this link with the material and social also presents limits: if innovation is a participative process that is (1) not entirely under human control and (2) certainly not entirely under individual control since embedded in broader and larger social-cultural-material patterns and structures, then a discourse about individual human responsibility is not sufficient. There should be more attention to the material, technological dimension of innovation poetics- to the participation of the technologies and their normative implications - and to the evaluation of the larger societal institutions and cultural patters, indeed the entire form of life, in which the innovation is embedded. For instance, evaluating gender bias in the design of devices for the household must be connected with an evaluation of institutions and societal structures (e.g. power structures); innovation is never isolated from such larger patterns. Games and forms of life have normative implications for innovation, art, and design. Therefore, ethics and politics of technological innovation cannot be content with only studying material artefacts, as the empirical turn in philosophy of technology proposed. Instead, material artefacts have to be understood as intrinsically connected to larger social and cultural wholes and patterns. If there is such a thing as the normative or morality of artefacts, then it is a normativity and morality that is deeply connected with "the way we do things" in particular social and cultural games and in a particular form of life. Those games and that form of life also need to be studied and evaluated. This renders philosophy and ethics of technology more critical and might contribute to technologicalsocietal change.

That being said, we should again acknowledge limitations to change: if, based on our evaluation, we want to change those games and that form of life, that may turn out to be very difficult. We can try, with new discourses, and especially with new practices, for instance artistic practices, innovation practices, and design practices (indeed discourse is not enough). However, such efforts at innovation and change have only limited effects on our form of life, since they are themselves shaped by larger "grammars". On the account presented, then, it may well be true that art can change the world, and that design can change the world. But such change is only possible if there are sufficient shifts in the entire holistic configurations in which individual and human material-poetic performances participate. Going against our modern(ist) desires and intuitions, we should acknowledge that such shifts are always limited and that radical technological-cultural change is neither possible nor desirable. To think that we can turn all the stones at once is a dangerous illusion that has brought much misery and suffering to humankind. We better start with shifting a few pebbles.

Acknowledgements Open access funding provided by University of Vienna. 
Open Access This article is distributed under the terms of the Creative Commons Attribution 4.0 International License (http:// creativecommons.org/licenses/by/4.0/), which permits unrestricted use, distribution, and reproduction in any medium, provided you give appropriate credit to the original author(s) and the source, provide a link to the Creative Commons license, and indicate if changes were made.

\section{References}

Coeckelbergh M (2017) Using words and things: language and philosophy of technology. Routledge, New York, Abingdon

Dewey J (1925) Experience and nature. George Allen \& Unwin, London

Francisco S (2007) The way we do things around here: specification versus craft culture in the history of building. Am Behav Sci 50(7):1-19

Garcia R, Calantone R (2002) A critical look at technological innovation typology and innovativeness terminology: a literature review. J Prod Innov Manag 19:110-132

Haseman B (2006) A manifesto for performative research. Media Int Aust 118(1): 98-106.

Heidegger M (1977) The question concerning technology. In: Heidegger $M$ (ed) The question concerning technology and other essays, trans. W Lovitt. Harper \& Row, New York

Latour B (1993) We have never been modern (trans: C Porter). Harvard University Press, Cambridge

Latour B (2004) Politics of nature: how to bring the sciences into democracy (trans: C Porter). Harvard University Press, London

Lees-Maffei G, Sandino L (2004) Dangerous liaisons: relationships between design, craft and art. J Des Hist 17(3):207-219

Owen R, Macnaghten P, Stilgoe J (2012) Responsible research and innovation: from science in society to science for society, with society. Sci Pub Pol 39:751-760
Oxman N (2016) Age of entanglement. J Des Sci 1. http://jods.mitpress.mit.edu/pub/AgeOfEntanglement. Accessed 6 Feb 2017

Pickering A (1995) The mangle of practice: time, agency, and science. University of Chicago Press, Chicago

Polanyi M (1966a) The tacit dimension, 2009 edn. The University of Chicago Press, London

Polanyi M (1966b) The creative imagination. Chem Eng News 44(17):85-93

Popper KR (1962) The open society and its enemies, vol 1, 5th revised edn. Princeton University Press, Princeton

Reason P (1998) Political, epistemological, ecological and spiritual dimensions of participation. Stud Cult Org Soc 4:147-167.

Rust C (2004) Design inquiry: tacit knowledge and invention in science. Des Issues 20(4):76-85

Verbeek P-P (2014) On icarus' wings: craft and the art of hybridization. In: DIS' 14 Proceedings of the 2014 conference on designing interactive systems. Vancouver, BC, Canada, June 21-25, 2014. ACM Digital Library. http://dl.acm.org/citation.cfm?id $=2605003 \& \mathrm{dl}=\mathrm{ACM} \& \mathrm{coll}=\mathrm{DL} \& \mathrm{CFID}=737254438 \& \mathrm{CFTO}$ $\mathrm{KEN}=65288032$. Accessed 6 Feb 2017

Vom Schomberg R (2013) A vision of responsible research and innovation. In: Owen R, Heintz M, Bessant J (eds) Responsible innovation. John Wiley, London, pp. 51-74

Winner L (2014) Technologies as forms of life. In: Sandler R (ed) Ethics and emerging technologies. Palgrave Macmillan, Basingstoke, pp. 48-60

Wittgenstein L (1969) In: Anscombe GEM, von Wright GH (eds) On certainty (trans: D Paul and GEM Anscombe). Basil Blackwell, Oxford

Wittgenstein L (2009) In: Anscombe GEM, Schulte J (eds) Philosophische untersuchungen/philosophical investigations, revised 4th edn (trans: Anscombe GEM, Hacker PMS, Schulte J). WileyBlackwell, Malden 